\title{
NUEVOS RETOS Y PERSPECTIVAS PARA EL FARMACÉUTICO EN EUROPA
}

\author{
MANUEL MACHUCA GONZÁLES
}

UNIVERSIDAD DE GRANADA, ESPAN̄A

En los últimos meses se han conocido dos novedades importantes en el panorama farmacéutico europeo, que sin duda van a marcar el futuro de nuestra profesión, y que se reseña:

- La aparición de las primeras estatinas como medicamentos OTC.

- La autorización de los primeros farmacéuticos prescriptores en el Reino Unido.

Los medicamentos OTC, son aquellos que no necesitan la prescripción de un médico para ser dispensados, pudiendo el farmacéutico hacerlo libremente, e incluso indicarlo cuando pueda considerar que el paciente lo necesita. Esto tiene además una particularidad adicional, ya que en los paises anglosajones europeos, los medicamentos OTC pueden adquirirse en las estanterias de los supermercados, sin la supervisión de un farmacéutico, a diferencia de los países latinos de Europa, en los que la dispensación de cualquier medicamento corresponde a las farmacias.

Por otra parte, la prescripción de medicamentos ha sido una tarea tradicionalmente asignada al médico. Aungue ha existido el concepto de automedicación, interpretada de una forma más ortodoxa en unos países que en otros, y en España apareció el de Indicación farmacéutica, en desarrollo en la actualidad, para definir la actuación del farmacéutico ante la consulta por parte de un paciente para tratar un síntoma menor, nunca hasta ahora se había autorizado a farmacéuticos a realizar la prescripción de medicamentos para patologías más importantes. Por lo que se ve, no todos los farmacéuticos británicos van a estar autorizados para realizar esta función, sino que necesitará un examen, y las circunstancias de autorización estarán bien definidas y no serán validas en todo. Pero el camino está abierto.

Tanto el caso de las estatinas $\mathrm{OTC}_{\text {, como el de los }}$ farmacéulicos prescriptores han tenido, detractores en los sectores más conservadores de ambas profesiones y defensores, en los más avanzados. De lo que no cabe duda alguna es que nada es casual en lo que se refiere a la ciencia.

Hay que ser consistente de que lo que está ocurriendo, se debe a la evolución de la demanda de la atención sanitaria por parte de los pacientes, así como los cambios que la profesión farmacéutica está experimentando a nivel mundial, lo que provocará sin duda la aparición de nuevas responsabilidades, $y$, por lo tanto, modificaciones en la formación universitaria y en el papel de los farmacéuticos ante la sociedad.

Las estatinas han demostrado su beneficio en la prevención de las enfermedades cardio y cerebro vasculares. Recientemente, investigadores españoles han abierto otra línea muy prometedora, al encontrar que pueden tener una gran utilidad en el SIDA, al demostrar su capacidad de disminuir la carga viral en los pacientes. Está claro que son unos grandes medicamentos y que la prevención de las enfermedades vasculares es un reto en la sociedad. Por lo tanto, al aparecer estatinas OTC, se está pidiendo al farmacéutico un papel más activo como agentes de salud pública en medicina preventiva.

La aparición de farmacéuticos prescriptores viene como consecuencia de ser profesionales tan accesibles como desaprovechados, y en muchas ocasiones desmoralizados por las presiones de la industria farmacéutica, los sistemas mercantilistas de salud o los estados. La prescripción por parte del farmacéutico, en las circunstancias que se determinen, viene a suponer la demanda de su integración plena dentro de los equipos de salud y su implicación a tareas preventivas. Se puede comprobar, por tanto, que dos noticias paralelas, tienen un fondo común. El papel del farmacéutico está cambiando y, por mucho que intenten los sectores más reaccionarios de la profesión en todo el mundo, nada se puede hacer para detener el cambio, porque así lo está cxigiendo la sociedad. Sería como poner puertas en el campo o diques al mar. Este cambio va a enriquecer la profesión, aportando nuevas facetas, cambios en los programas docentes y curriculares y nuevas responsabilidades, que sin duda contribuirán a mejorar el nivel de salud de la sociedad a la que sirve.

El movimiento de la Atención Farmacéutica, los farmacéuticos prescriptores, medicamentos OTC. Todo va en la misma dirección. 